\title{
TEMPORAL CONTEXT AND THE PERCEPTIONS OF GERIATRIC PATIENTS*
}

\author{
WiLliam Rakowski $\dagger$ \\ Health Gerontology Program, School of Public Health II, Room M5116, University of Michigan. \\ 109 S. Observatory St, Ann Arbor, MI 48109, U.S.A.
}

\begin{abstract}
The prevalence in later life of long-term, chronic conditions requires that researchers and clinical professionals become sensitive to the temporal context of older persons' personal and healthrelated perceptions. A sample of patients at a geriatric ambulatory clinic responded to a questionnaire sent prior to their initial appointment. The present report focuses on expectations regarding future health and treatment, general personal future projection, and perceptions of current health. Present self-rated health status and future projection were significant associates both of anticipated future health and treatment expectations. However, questions directed toward when treatment benefits were expected to begin and for how long treatment might last were characterized by few predictors. Indications of optimism and uncertainty about future health and treatment were both represented, although neither general optimism nor general uncertainty appeared in a large segment of the sample. Results suggest the salience of future perspective for older adults in the health care setting. and the complexity which may be encountered as treatment progresses.
\end{abstract}

Recognition of the inevitable growth and significance of geriatric health care has stimulated efforts to identify psychosocial factors that contribute to the context in which care is sought by and delivered to older adults $[1-4]$. The scope of this task is particularly evident in view of the chronic nature of most later life health problems. Since these conditions extend and are treated over time, health professionals and researchers should be aware of the various temporal perspectives which may be brought to the care setting by older adults. Based on this need, the present report examines older adults' expectations of treatment and future health, along with their general future perspective, as potential elements of the health care context.

Three questions were of major interest. One was the existence of general optimism and uncertainty in regard to anticipated future health and treatment. Second, associations among these indices were examined, as well as their relationship with perceptions of present health. Finally, because perceptions of the personal future are a salient element of later adulthood [5-7], another question dealt with the extent to which future thinking and planning were associated with anticipated health and treatment.

\section{PATIENT.SAMPLE}

Data were collected from 132 community-residing persons ( 95 women, 37 men), who were new patients

* This research was supported by a Faculty Research Grant from the Horace H. Rackham School of Graduate Studies. The University of Michigan. Project No. FRR387519.

+ The author wishes to thank Dr Ivan F. Duff, Florence J. Tillman, RN, and staff of the Turner Geriatric Clinic for their cooperation in the research upon which this report is based; and Dr Tom Hickey for his review and comments during preparation of the manuscript. a university-based, geriatric ambulatory clinic. All participants were volunteers, and like the existing patient census were almost exclusively caucasian, had an average age of 73.06 years (range: 60-92 years), and represented primarily average and above average socioeconomic backgrounds.

\section{DATA COLLECTION}

After instrument development at the clinic $(n=44)$, all new patients over a 1 year period were contacted before their initial appointment, through a cover letter and 6-page questionnaire included in materials routinely sent by the clinic. Persons willing to participate brought the completed questionnaire with them at the time of their appointment. Approximately onehalf of the new patients during this period provided usable questionnaires. Individuals not participating tended to be those who did not perceive any noticeable health problem; persons awaiting only a routine check-up; and persons with visual, motor, or cognitive impairments which prohibited completing the instrument.

\section{VARIABLES OF INTEREST}

Open-ended and multiple-choice questions were used. An important consideration was the diversity of responses which future-oriented questions can evoke from a sample of older adults. In particular, expressions of uncertainty and non-response were treated as meaningful answers. The variables of specific interest included:

(a,b) Future projection: defined as the distance of future thinking and planning. Each was assessed by an open-ended question, with responses categorized as: Near ( $\leqslant 1$ year or less), Intermediate ( $2-10$ years), Far (> 10 years. or rest of one's life). and No Response. 
(c,d) Self-rated health: assessed by a pictoral lifegraph' of the 5-year past, the present, and the 5-year future: each using a scale of Excellent to Poor. Variables were created for present and future health, with responses collapsed to: Above Average. Average. Below Average, and (for the future rating) Not Sure/No Response.

(e) Likelihood of additional health problems in the coming months; assessed on a five-point scale ("No chance at all" to "Certain that I will"), with an option for indicating uncertainty. Responses were collapsed to: Not Likely, 50/50 or Greater, and Not Sure.

(f) Perceived seriousness of current problems; measured on a three-point scale ("Not serious at all" to "Extremely Serious"), also with an option for uncertainty. Responses were collapsed to: Not Serious, Relatively Serious, and Not Surc.

(g) Areas of life affected by health problems; respondents indicating any or all of nine possible impacts (e.g. time it takes to do things, visiting family and friends). Responses were categorized as Two or Less vs Three or More affected areas.

(h) Anticipated onset of treatment benefits: based upon an open-ended question. Due to non-specific estimates, categories formed were: Soon. Not Sure. and No Response.

(i) Anticipated duration of treatment: also based upon an open-ended question. Again due to non-specificity, responses were collapsed to: Long. Not Sure. and No Response.

$(\mathrm{j}, \mathrm{k})$ Expected difficulty of making clinic tisits and of treatment: each assessed on a five-point scale ("Not hard at all" to "A major problem"), also with an option for uncertainty. Responses for both variables were categorized as: Little Difficulty. Noticeable Difficulty, and Not Sure.

Responses to open-ended items were coded independently by two persons other than the investigator. Rates of agreement were consistently over $90^{\circ}$.

\section{RESULTS}

\section{General uncertainty and oprimism}

Although optimism and uncertainty were both clearly evident on the univariate level, individuals tended not to follow a dominant pattern across several variables. Relationships were limited to pairs of indices.

Future health. Persons who expressed uncertainty about both the likelihood of near future problems and 5 -year future health comprised only $17^{\circ} \%$ of the total sample. (This figure included non-response, which appeared to be an indicator of uncertainty.) Similarly, from the standpoint of apparent optimism, only $14^{\circ}$ \% expected no appreciable likelihood of new near future problems and to be in above average health in 5 years. Other category combinations were similarly non-dominant.

Conditional probabilities indicated that the 5-year future index was more predictive of near future perceptions, than the near future index was of the 5-year future health expectation.

Treatment expectations. The largest percentage of the sample expressing uncertainty (including non-response) for any pair of variables occurred for onset of benefits and treatment duration $\left(58^{\circ} \%\right)$. The lowest percentage was observed for difficulty of treatment and clinic visits $\left(8^{\circ}{ }_{0}\right)$. The majority for all possible pairs did not exceed $30^{\circ}{ }_{\circ}$ of the sample. Since joint uncertainty was so disparate for pairs of variables, uncertainty across all four treatment expectation indices was not characteristic of the sample.

The clearest indication of general optimism occurred for the $50^{\circ}$ of the sample who expected little difficulty with both clinic visits and treatment. Conditional probabilities reflected this association (Treatment $\mid$ Visit $=77^{\circ}$, optimistic on both; Visit Treatment $=87^{\circ}$, optimistic on both). All other pair combinations showed markedly lower percentages, so that similar to uncertainty, indications of general optimism were not apparent across all four treatment expectation indices.

\section{Health and treatment expertations}

Future health. The near future and 5-year future indices were combined, creating four groups: Uniformly Favorable; Uniformly Unfavorable; Uncertain for both; Favorable Near. but not far.

Present health ratings were significantly associated with this combined index (see Table 1). A uniformly favorable perspective was most evident among persons in the above average life-graph group $\left(65^{\circ}\right)$, and who rated their problems to be not very serious $\left(52^{\circ}\right)$. Another $20^{\circ}{ }_{0}$ of the former group, and $36^{\circ}$ of the latter, were in the favorable near future group. In contrast, expecting uniformly unfavorable future health was greatest for the average and below average life-graph groups $\left(46,59^{\circ}\right)$, and for the relatively serious and uncertain seriousness groups $(49,51 \%)$.

The future health index was a predictor of number of affected life areas, with $85_{\%}^{\circ}$ of the uniformly favorable group reporting two or fewer, in contrast to $35^{\circ}$, of the uncertain group and $42^{\circ}$ of the unfavorable group.

In regard to future thinking and planning, among the uniformly favorable group. $75^{\circ}$ thought and $73 \%$ planned two or more years ahead. In contrast, only $37-39^{\circ}{ }_{\circ}$ of the unfavorable group. and $13-15^{\circ} \%$ of the uncertain group. thought or planned for that far. In addition. $69^{\circ}$ of the uncertain group projected one year or less, while $61^{\circ}$ planned one year or less.

The uniformly favorable future health group showed the highest percentages of persons expecting no difficulty with treatment $\left(94^{\circ}\right)$ or with visits $\left(93^{\circ}\right)$; while the lowest percentages occurred for the uniformly uncertain $\left(50,67_{0}^{\circ}\right)$ and unfavorable groups $\left(27,54^{\circ}\right)$

Relative to onset of benefits, persons uniformly uncertain of future health were most likely to be unsure of when benefits would begin $(63 \%$; with $31 \%$ not responding). Similarly, $51 \%$ of the uniformly unfavorable group did not respond, and another $25 \%$ were not sure. The highest percentages of persons who expected benefits soon occurred for the uniformly favorable $\left(41^{\circ}\right)$.

The association with expected duration of treatment was even more basic. Persons in the uniformly favorable group were most likely to offer at least some estimate of duration $(86 \%)$, while the unfavorable group was least likely to $(58 \%)$.

Treatment and visit difficulty. Treatment and visit difficulty were combined, forming two groups: No Difficulty in either vs All Other. 
Table 1. Summary of associations between combined indices, present and future health, treatment expectations, and future projection

\begin{tabular}{|c|c|c|c|}
\hline Associates & $\begin{array}{l}\text { Future } \\
\text { health }\end{array}$ & $\begin{array}{l}\text { Visit/ } \\
\text { treatment }\end{array}$ & $\begin{array}{l}\text { Benefit/ } \\
\text { duration }\end{array}$ \\
\hline 1 Life-graph: present & $\begin{array}{c}45.59 * \pi \\
\text { Phi }=0.47\end{array}$ & $\begin{array}{c}11.50 \pi \\
\text { Phi }=0.34\end{array}$ & 0.48 \\
\hline 2 Seriousness & $\begin{array}{c}38.05 \pi \\
\text { Phi }=0.42\end{array}$ & $\begin{array}{c}9.84 \S \\
\text { Phi }=0.31\end{array}$ & 3.31 \\
\hline 3 Affected life areas & $\begin{array}{c}10.56 \ddagger \\
\text { Phi }=0.33\end{array}$ & $\begin{array}{c}3.79 \ddagger \\
\text { Phi }=0.21\end{array}$ & 1.70 \\
\hline 4 Future thinking & $\begin{array}{c}24.10 \mathrm{I} \\
\mathrm{Phi}=0.29\end{array}$ & $\begin{array}{c}22.069 \\
\mathrm{Phi}=0.46\end{array}$ & $\begin{array}{c}17.26 \pi \\
\text { Phi }=0.44\end{array}$ \\
\hline 5 Future planning & $\begin{array}{c}19.32 \ddagger \\
\text { Phi }=0.26\end{array}$ & $\begin{array}{c}15.20 \pi \\
\mathrm{Phi}=0.38\end{array}$ & $\begin{array}{c}19.52 \pi \\
\text { Phi }=0.47\end{array}$ \\
\hline 6 Treatment difficulty & $\begin{array}{c}31.90 \pi \\
\text { Phi }=0.38\end{array}$ & - & 1.24 \\
\hline 7 Visit difficulty & $\begin{array}{c}11.38 \dagger \\
\text { Phi }=0.25\end{array}$ & - & 3.05 \\
\hline 8 Benefit onset & $\begin{array}{c}13.24 \dagger \\
\text { Phi }=0.25\end{array}$ & $\begin{array}{c}7.14 \ddagger \\
\text { Phi }=0.27\end{array}$ & - \\
\hline 9 Treatment duration & $\begin{array}{c}17.09 \\
\mathrm{Phi}=0.31\end{array}$ & $\begin{array}{c}15.389 \\
\mathrm{Phi}=0.39\end{array}$ & - \\
\hline 10 Future health: (combined) & - & $\begin{array}{c}28.46 \pi \\
\text { Phi }=0.55\end{array}$ & 1.30 \\
\hline
\end{tabular}

- Note: Top number represents chi-square value from tests of association.

$+P \leqslant 0.10 ; \ddagger P \leqslant 0.05: \$ P \leqslant 0.01: \rrbracket P \leqslant 0.005$

Expecting no difficulty was most frequent among persons describing their health as above average $(83 \%)$, and their problems as not serious $(81 \%)$. In contrast, expecting no difficulty was least common among the average and below average life-graph groups $(38,44 \%)$; and the uncertain and relatively serious groups $(42,43 \%)$. Similarly, persons reporting two or fewer areas of life were more likely to expect no difficulty than persons reporting three or more ( 58 vs $37^{\circ} \%$ ).

Persons thinking more than 10 years were most likely to anticipate no difficulty $(75 \%)$, followed by the 2-10 year group $\left(63^{\circ}\right)$, the less than 1 year group $(45 \%)$, and persons who did not respond $(12 \%)$. Future planning was comparable, the figures being 68 , 67,42 , and $20 \%$.

For the combined future health index, the largest percentage of persons expecting no difficulty occurred in the uniformly favorable group $(88 \%)$, followed by persons in the group expecting no new near future problems $(77 \%)$. The uniformly negative group showed the lowest $(19 \%)$, while the uncertain group was more evenly split ( 54 vs $46^{\circ} \%$ ).

Finally, for both benefit onset and treatment duration, persons who did not respond also had the lowest rates of anticipating no difficulty $(37 \%$ and $25 \%$ ). All other benefit and duration subgroups had at least $53^{\circ}{ }_{n}$ who expected no difficulty, so that offering any type of answer was associated with a more favorable outlook on difficulty.

Treatment benefit and duration. The large degree of uncertainty in these areas was evident in the minimal number of associates, with only distance of future thinking and planning achieving significance.

Specifically, persons who offered any temporal estimate of projection at all-whether near or far, quantitative or qualitative-were more likely to offer some response to the benefits/duration questions $(82-93 \%)$. In contrast, persons not responding to the future projection items were most likely also not respond to the benefits/duration questions $(55 \%)$.

\section{Personal future projection}

As indicated in Table 1, and the above discussion, future thinking and planning were associated with the three combined indices. Although shorter projection (less than 1 year) tended to be associated with less favorable or less optimistic responses in other areas, persons not responding at all presented an even less positive set of perceptions. Further thinking and planning ( 2 years or more) tended to indicate a more favorable outlook.

\section{DISCUSSION}

The present data provide a basis for further investigating future perspective among geriatric patients. Prospective studies are necessary to determine whether, or to what extent, various temporal perspective are associated with different outcomes as treatment proceeds. For example, are persons with broadly favorable health expectations better able to handle temporary exacerbations of chronic conditions than are older adults with broadly unfavorable expectations? Similarly, are patients with either uniformly favorable or unfavorable expectations less likely to change their perspective than patients who enter treatment with a less uniform outlook?

An additional piece of potentially useful information for prospective studies relates to the depressive state of the respondents. It is conceivable that even a mild depression may mediate the relationship 
between self-rated physical health and future perspective, and in turn be a more powerful predictor of long-term health behavior.

Further research should also be prepared for complexities likely to be encountered. For example, not every dependent variable pair was comparably predicted, raising the possibility that some expectations (e.g. benefit onset and treatment duration) exist relatively independently from other future perceptions. Investigators should not be surprised to encounter a preference for qualitative, as opposed to easily quantified responses. Additionally, the variables used here represented general beliefs and perceptions. Subsequent research can usefully focus on the extent to which lines of specific questioning can be pursued early in contact for a particular condition or symptom. Finally, present health ratings may be examined as indirect indicators of an older patient's future health expectations.

\section{REFERENCES}

1. Aho W. R. Participation of senior citizens in the swine flu innoculation program: An analysis of health belief model variables in preventive health behavior. J. Geront. 34, 201, 1979.

2. Haug M. Doctor patient relationships and the older patient. J. Geront, 34, 852. 1979.

3. Haynes R. B. Sackett D. L. and Taylor D. W. How to detect and manage low patient compliance in chronic illness. Geriatrics 35, 91, 1980

4. Rakowski $W$. and Hickey $T$. Late life health behavior: Integrating health beliefs and temporal perspectives. Res. Aging 2, 283, 1980.

5. Kastenbaum R. J. Time. death and ritual in old age. In The Study of Time II (Edited by Fraser J. T. and Lawrence N.), p. 20. Springer-Verlag. New York, 1975.

6. Neugarten B. L. Time. age. and the life cycle. Am. J. Psychiar. 136, 887, 1979.

7. Rakowski W. Future time perspective in later adulthood: review and research directions. Exp. Aging Res. 5, 43, 1979. 